\title{
Establishment and characterization of a triple negative basal-like breast cancer cell line with multi-drug resistance
}

\author{
SERGEI BOICHUK, AIGUL GALEMBIKOVA, ALEXANDR SITENKOV, RAMIL KHUSNUTDINOV, \\ PAVEL DUNAEV, ELENA VALEEVA and NATALIA USOLOVA
}

Department of Pathology, Kazan State Medical University, Kazan 420012, Russia

Received March 2, 2017; Accepted June 21, 2017

DOI: $10.3892 / 01.2017 .6795$

\begin{abstract}
Triple-negative breast carcinoma (TNBC) is one of the most aggressive subtypes of breast cancer and is associated with an unfavorable prognosis. The management of TNBC is currently based on the use of classical cytotoxic drugs, i.e., anthracyclines and/or microtubule-binding agents (TBAs). However, conventional chemotherapy is not always effective in these tumors and a systemic relapse is often observed, potentially due to the development of multi-drug resistance (MDR). Therefore, an improved understanding of MDR mechanisms may improve the therapeutic strategies for TNBC. In the present study, a paclitaxel-resistant (TxR) breast cancer cell subline of HCC1806 TNBC cells was established and characterized. The resistance index of this subline was calculated according to the $\mathrm{IC}_{50}$ of $\mathrm{HCC} 1806-\mathrm{TxR}$ relative to the parental HCC1806 cells (16.86-fold). TxR-cells also exhibited cross-resistance to vinblastin, doxorubicin and etoposide ( 14-, $\sim 4$ - and $\sim 3$-fold, respectively). As assessed with reverse transcription-quantitative polymerase chain reaction, TxR-resistant cells exhibited the upregulated expression of a number of multidrug resistance-associated genes, including MDR-1, MRP-1, -5, -6 and YB-1. The TxR cells also exhibited an increased expression of MDR-related proteins including MDR1 and MRP-1, which led to a substantial increase (5.4-fold) of the paclitaxel efflux from TxR-cells. In addition, the pro-apoptotic protein Fas was downregulated, whereas the anti-apoptotic Bcl-2 was upregulated, in TxR-cells. This may explain why a reduced extent of apoptosis was observed when TxR cells were exposed to TBAs and topoisomerase type II inhibitors, relative to the parental HCC1806 cells. Thus, the HCC1806-TxR cell line may serve as an appropriate model for the analysis of chemoresistance mechanisms in TNBCs, and
\end{abstract}

Correspondence to: Professor Sergei Boichuk, Department of Pathology, Kazan State Medical University, 49 Butlerov Street, Kazan 420012, Russia

E-mail: boichuksergei@mail.ru

Key words: triple negative basal-like breast cancer, apoptosis, chemoresistance, paclitaxel, P-glycoprotein for the investigation of novel anticancer agents for overcoming MDR-mediated mechanisms in TNBC.

\section{Introduction}

A total of $12-25 \%$ of all cases of breast cancer are characterized by the lack of expression of the estrogen receptor and progesterone receptor in addition to the absence of the overexpression of human epidermal growth factor receptor-2 (HER-2), and are therefore classified as triple-negative breast cancer (TNBC) (1). TNBC is amongst the most aggressive subtypes of breast cancer, which is unresponsive to hormonal therapy and HER-2-targeted antibody therapy (2). Thus, TNBC is characterized by poor overall survival time, predominantly due to the unavailability of strategies for specific therapy. Cytotoxic chemotherapy is currently the main therapeutic option for TNBC (2), including anthracyclines (for example doxorubicin) and/or microtubule-binding agents (TBAs; such as taxans). The molecular mechanism of action for TBAs is associated with cell cycle arrest, predominantly at G2/M; apoptosis is induced as a consequence of mitotic exit failure or 'mitotic catastrophe' (3-5). A number of TBAs are in broad use in the clinical treatment of TNBC. Although certain patients initially respond to these classical cytotoxic drugs, patients exhibit high rates of systemic relapse during early stages and decreased overall survival times following metastasis $(6,7)$. This may be due to drug resistance development arising from the overexpression of drug-efflux pumps, including the multidrug resistance (MDR)-associated transporter P-glycoprotein (MDR-1) or proteins from the MDR-associated protein (MRP) family, collectively members of the ATP-binding cassette (ABC) transporter superfamily $(8,9)$.

Furthermore, non-target-specific chemotherapy is toxic, and the use of anthracyclines and TBAs is limited by multiple side-effects, including cardiotoxicity, myelo- and immunosuppression, neutropenia, mucositis and fluid retention; the drugs also exhibit low bioavailability. Thus, there is an urgent requirement for the development of novel, safe, and effective therapeutic options for TNBC. To achieve this goal, appropriate models for the analysis of the mechanisms to bypass MDR in TNBC are required.

In the present study, a paclitaxel-resistant (TxR) HCC1806derived breast cancer cell subline that harbored a MDR phenotype, with cross-resistance to anthracyclines and TBAs, was 
established and characterized. This HCC1806-TxR TNBC subline may serve as an appropriate model for analyzing the chemoresistance mechanisms of TNBC, and to allow the study of potential novel methods for bypassing MDR.

\section{Materials and methods}

Chemical compounds. Doxorubicin, paclitaxel, vinblastine and cisplatin were purchased from Sigma-Aldrich (Merck KGaA, Darmstadt, Germany); etoposide was obtained from Calbiochem (EMD Millipore, Billerica, MA, USA).

Antibodies. The primary antibodies used for western blotting and flow cytometry were as follows: anti-ABC subfamily $\mathrm{G}$ member 2 (ABCG-2; cat. no. 42078P; Cell Signaling Technology Inc., Danvers, MA, USA), Alexa-488-conjugated anti-phosphorylated histone subunit $\mathrm{H} 3 \mathrm{~S} 10$ (pH3 S10; cat. no. 9708S; Cell Signaling Technology Inc., Danvers, MA, USA), cleaved caspase-3 (cat. no. 9661S; Cell Signaling Technology, Inc.), anti-PARP (cat. no. 436400; Invitrogen; Thermo Fisher Scientific, Inc., Waltham, MA, USA), MDR-1 (cat. no. sc-55510) MRP-1 (cat. no. sc-18835) and $\beta$-actin (cat. no. sc-8432; Santa Cruz Biotechnology, Dallas, TX, USA); HRP-conjugated secondary antibodies [anti-mouse immunoglobulin (Ig)G, cat. no. sc-2005; anti-rabbit IgG, cat . no. sc-2004] for western blotting were purchased from Santa Cruz Biotechnology, Inc.

Cell lines and culture conditions. MES-SA/Dx5 Cell Lysate was obtained from Santa Cruz Biotechnology (cat. no. sc-2284). The human basal-like TNBC cell line, HCC1806, was purchased from American Type Culture Collection (Manassas, VA, USA) and maintained in RPMI-1640 medium supplemented (Paneco, Moscow, Russia) with 10\% fetal bovine serum (Gibco; Thermo Fisher Scientific, Inc., Waltham, MA, USA), $1 \%$ L-glutamine, $50 \mathrm{U} / \mathrm{ml}$ penicillin and $50 \mu \mathrm{g} / \mathrm{ml}$ streptomycin. To establish a TxR TNBC subline, HCC1806 cells were initially incubated in $0.5 \mathrm{nM}$ paclitaxel for 4 weeks. When stable growth was achieved, the paclitaxel concentration was doubled every 4-5 weeks over 8 months to a maximum dose of $100 \mu \mathrm{M}$. Prior to experimental use, TxR-cells were maintained in paclitaxel-free culture medium as previously described, and passaged at least 3 times. All cells were cultured at $37^{\circ} \mathrm{C}$ in a humidified atmosphere of $5 \% \mathrm{CO}_{2}$ in an incubator (Lamsystems, Miass, Russia) throughout the present study.

Intracellular drug concentration. HCC1806 and HCC1806-TxR cells were exposed to $100 \mathrm{nM}$ paclitaxel for 2 h. Cells were rinsed twice with ice-cold PBS, harvested into centrifuge tubes, centrifuged at $250 \mathrm{x}$ g for $5 \mathrm{~min}$ at room temperature and collected for solid-phase extraction high performance liquid chromatography (HPLC; LC-20 Prominence; Shimadzu Corporation, Kyoto, Japan). The detection wavelength was $227 \mathrm{~nm}$ and the limit of detection for paclitaxel was $5.0 \mathrm{ng}$. Experimental conditions were as follows: mobile phase; water and acetonitrile in a ratio of 40:60; Ascentis ${ }^{\circledast} \mathrm{C} 18$ column, 4.6x250 mm; guard cartridge, Ascentis ${ }^{\circledR} \mathrm{C} 18$ Supelguard with $5 \mu \mathrm{m}$ particle size, 20x4 mm; isocratic mode (flow rate, $1 \mathrm{ml} / \mathrm{min}$; temperature, $40^{\circ} \mathrm{C}$; pressure, 35 bar; Sigma-Aldrich). Paclitaxel (Sigma-Aldrich) was used as the internal standard. The method of absolute calibration was used for the quantitation of paclitaxel. The intracellular concentration of paclitaxel was defined as the total amount of paclitaxel $/ 10^{6}$ cultured cells.

Cellular survival assay. Exponentially growing cells were seeded $\left(3.2 \times 10^{4}\right.$ cells/well) into the 96 -well flat-bottomed plates (Corning Incorporated, Corning, NY, USA) and incubated for $24 \mathrm{~h}$ at $37^{\circ} \mathrm{C}$ with RPMI-1640 culture medium. The cells were then cultured for 24 or $48 \mathrm{~h}$ at a range of concentrations of chemotherapeutic agents, including paclitaxel $(1 \mathrm{nM}-10 \mu \mathrm{M})$, doxorubicin $(0,03125-8 \mu \mathrm{g} / \mathrm{ml})$, vinblastine $(1 \mathrm{nM}-10 \mu \mathrm{M})$, cisplatin $(0,03125-80 \mu \mathrm{M})$ or etoposide $(2,5-640 \mu \mathrm{M})$. All the aforementioned agents were previously diluted in dimethyl sulfoxide (DMSO). DMSO was used as a negative control in untreated cells. MTS reagent (CellTiter 96® Aqueous Non-Radioactive Cell Proliferation Assay; Promega Corporation, Madison, WI, USA) was added at $2 \mathrm{mg} / \mathrm{ml}$ to assess the relative number of viable cells. The MTS and cells were incubated for $\geq 1 \mathrm{~h}$ and the production of formazan, dissolved using DMSO, was assessed by the relative absorbance at $492 \mathrm{~nm}$ on a MultiScan FC plate reader (Thermo Fisher Scientific, Inc.). The resulting $\mathrm{IC}_{50}$ values were defined as the compound concentration required to inhibit cellular growth by $50 \%$ after $48 \mathrm{~h}$ of post treatment. The data was normalized to the DMSO control group.

Real-time monitoring of cell proliferation using an i-CELLigence system. An in vitro growth curve characterization of HCC1806 parental and TxR cells cultured in the presence of paclitaxel was performed using an iCELLigence system (ACEA Biosciences, Inc., San Diego, CA, USA). Cells $\left(5 \times 10^{4}\right)$ were seeded in electronic microtiter plates (E-Plate; Roche Diagnostics, Basel, Switzerland) and incubated for $24 \mathrm{~h}$ to obtain the growth baseline reading. Then cells were treated with 10,50 or $100 \mathrm{nM}$ paclitaxel in triplicate, and cell index (CI) measurements were obtained, with a signal detected every 30 min until the end of the experiment $(72 \mathrm{~h})$. Normalized CI values were calculated with RTCA iCelligence software version 1.1.1 (Roche Diagnostics).

Western blot analysis. For western blot analysis, whole-cell extracts were prepared by scraping HCC1806 parental and TxR cells, or MES-SA control cells, into radioimmunoprecipitation buffer (1\% NP-40, $50 \mathrm{mM}$ Tris- $\mathrm{HCl} \mathrm{pH} 8.0$, supplemented with protease and phosphatase inhibitors). The cellular lysates were incubated for $1 \mathrm{~h}$ at $4^{\circ} \mathrm{C}$ and then clarified by centrifugation for $30 \mathrm{~min}$ at $14,000 \mathrm{x}$ g at $4^{\circ} \mathrm{C}$. Protein concentrations were measured by the Bradford assay. Samples containing $30 \mu \mathrm{g}$ of protein were resolved on $4-12 \%$ Bis-Tris or 3-8\% Tris-acetate NuPAGE gels (Invitrogen; Thermo Fisher Scientific, Inc.), transferred to a nitrocellulose membrane (Bio-Rad Laboratories, Inc., Hercules, CA, USA), probed with primary $\left(1: 1,000\right.$ and incubated overnight at $\left.4^{\circ} \mathrm{C}\right)$, and secondary antibodies (1:1,000 and incubated for $1 \mathrm{~h}$ at room temperature) and visualized with enhanced chemiluminescence (Western Lightning Plus-ECL reagent, PerkinElmer, Inc., Waltham, MA, USA). The MES-SA cells acted as a positive control for $\mathrm{ABC}$ protein expression. 
Table I. Primers for quantitative polymerase chain reaction.

\begin{tabular}{lll}
\hline Gene & \multicolumn{1}{c}{ Forward } & \multicolumn{1}{c}{ Reverse } \\
\hline GAPDH & GACCACAGTCCATGCCATCA & TCCACCACCCTGTTGCTGTA \\
P-glycoprotein & ATGCTCTGGCCTTCTGGATGGGA & ATGGCGATCCTCTGCTTCTGCCCAC \\
MRP-1 & GCATGA TCCCTGAAGACGA & TAGAGCTGGCCCTTGTACTC \\
MRP-2 & TAGAGCTGGCCCTTGTACTC & TCAACTTCCCAGACATCCTC \\
MRP-3 & CGCCTGTTTTTCTGGTGGTT & TCCCCCAGTCACAAAGATG \\
MRP-4 & GCTGAGAATGACGCACAGAA & TCCCAGCAAGGCACGATATT \\
MRP-5 & GTCCTGGGTATAGAAGTGTG & CAGAAGATCCACACAACCCT \\
MRP-6 & TTGGATTCGCCCTCATAGTC & TCTTTTGGTCTCAGTGGCCT \\
Bel-2 & CTCCCACTGGATCTCTCAGC & TCGCATACACGGTGAGGTAG \\
Bcl-2 associated X & ATGTCCAGCCAGCTGCACCTGAC & GCAGAGTCTTCAGAGACAGCCAGG \\
Fas & GCTTCAGGGTTTCATCCAGG & AAAGTAGGAGAGGAGGCCGT \\
Caspase-8 & CAGGCTAACCCCACTCTATG & TGGGGGTGCATTAGGCCATT \\
Y-box binding protein 1 & ACTTCAGACACCAGGCAGGGCT & GCCCCTGCATCCAAGTGTGTTC \\
\hline
\end{tabular}

All primers are presented in the 5'-3' direction. MRP, multidrug resistance-associated protein.

Cell cycle analysis. For flow cytometry cell cycle analysis, the cells were treated with paclitaxel at 10 or $1,000 \mathrm{nM}$ for 24-48 h and trypsinized. Subsequent to centrifuging at $300 \mathrm{x}$ g for $5 \mathrm{~min}$ at room temperature, the cells were washed in PBS, fixed in $4 \%$ paraformaldehyde and permeabilized with ice-cold $90 \%$ methanol. The washed cells were stained with Alexa-488-conjugated anti-pH3 S10 (1:500 and incubated for $1 \mathrm{~h}$ at room temperature in the dark), were then counterstained with propidium iodide $(30 \mathrm{~min}$ at room temperature in the dark) (Sigma-Aldrich) and analyzed by fluorescence-activated cell sorting on a FC500 flow cytometer (Beckman Coulter, Inc., Brea, CA, USA). Cells were counted and analyzed using the Kaluza software version 1.3 (Beckman Coulter, Inc.).

RNA extraction and reverse transcription-quantitative polymerase chain reaction $(R T-q P C R)$. At $24 \mathrm{~h}$ after plating $1 \times 10^{6}$ HCC 1806 or HCC1806-TxR cells, total RNA was extracted using TRIzol reagent (cat. no. BC032; Invitrogen; Thermo Fisher Scientific, Inc.) according to the manufacturer's protocol and resuspended in diethyl pyrocarbonate-treated $\mathrm{H}_{2} \mathrm{O}$. RNA was reverse transcribed to cDNA using the Moloney murine leukemia virus reverse transcriptase kit (Evrogen JSC, Moscow, Russia) according to the manufacturer's protocol (cat. no. SK021), and subjected to qPCR. A total of $1 \mu$ l template cDNA was used in the qPCR reaction, with 5X qPCRmix-HS SYBR (Evrogen JSC) and $10 \mathrm{mM}$ of each forward and reverse primer (Table I). qPCR was performed with the CFX96 Real-Time detection system (Bio-Rad Laboratories, Inc.), according to the manufacturer's protocol. Thermal cycling conditions were as follows: $3 \mathrm{~min}$ at $95^{\circ} \mathrm{C}, 45$ cycles $(15 \mathrm{sec}$ at $95^{\circ} \mathrm{C}, 10 \mathrm{sec}$ at $56^{\circ} \mathrm{C}, 30 \mathrm{sec}$ at $72^{\circ} \mathrm{C}$ ) and a final extension step of $5 \mathrm{~min}$ at $72^{\circ} \mathrm{C}$. Each sample was processed in parallel with assays for GAPDH and the absolute levels of each mRNA were normalized relative to GAPDH. The $2^{-\Delta \Delta \mathrm{Cq}}$ method (10) was then used to calculate relative gene expression.
Statistical analysis. All experiments were repeated a minimum of 3 times. The results are presented as the mean \pm standard deviation for each group. Statistical analyses (Student's t-test, Mann-Whitney U test) were performed using Statistical software program version 7.0 (S.A. Glantz, McGraw Hill Education, NY, USA) and GraphPad Prism version 4.0 (GraphPad Software, Inc., La Jolla, CA, USA). P<0.05 was considered to indicate a statistically significant difference.

\section{Results}

Establishment of taxol-resistant HCC1806 breast cancer cell line. The HCC1806-TxR cell line was established following a continuous treatment with a gradually increasing concentration of paclitaxel, from $0.5-100 \mathrm{nM}$. Approximately 8 months and 55 passages were required to develop HCC1806 cells with stable drug resistance. It was then demonstrated that HCC1806-TxR cells were less sensitive to paclitaxel treatment when compared with parental HCC1806 cells; the paclitaxel drug resistance index was 16.86 (Table II). In addition to resistance to paclitaxel, HCC1806-TxR cells exhibited cross-resistance to vinblastine, doxorubicin and etoposide (drug resistance index, 14.65, 4.36 and 3.18, respectively), whereas there was no identified cross-resistance to cisplatin. Paclitaxel resistance in HCC1806-TxR cells remained stable following 1 month of culturing without paclitaxel and following storage at $-80^{\circ} \mathrm{C}$ for 6 months (data not shown).

Alterations in cellular morphology and growth kinetics. The morphology of the TxR cells was distinct from the parental cells. HCC1806-TxR cells exhibited an enlarged and oval-shaped morphology, and an increased nucleus/cytoplasm ratio when compared with the parental cells (Fig. 1A). The resistant cells were consistent in size and shape in monolayer proliferation, and their growth kinetics were different from those of the parental cells (Fig. 1B). When cells were cultured 
Table II. IC $_{50}$ values for HCC1806 and HCC1806-TxR cells.

\begin{tabular}{lccc}
\hline Drug & HCC1806 $(\%)$ & HCC1806-TxR $(\%)$ & Fold change \\
\hline Paclitaxel, $\mathrm{nM}$ & $4.68 \pm 0.44(9.39)$ & $78.9 \pm 3.8(4.8)$ & 16.86 \\
Vinblastine, $\mathrm{nM}$ & $0.2 \pm 0.04(20)$ & $2.93 \pm 0.32(10.92)$ & 14.65 \\
Doxorubicin, $\mu \mathrm{g} / \mathrm{ml}$ & $0.53 \pm 0.03(5.6)$ & $2.31 \pm 0.23(9.9)$ & 4.36 \\
Etoposide, $\mathrm{mM}$ & $72.94 \pm 9.64(10.6)$ & $231.91 \pm 15.73(3.1)$ & 3.18 \\
Cisplatin, $\mu \mathrm{M}$ & $10.27 \pm 1.09(13.2)$ & $10.19 \pm 0.32(6.8)$ & 1.01 \\
\hline
\end{tabular}

TxR, taxol resistant.
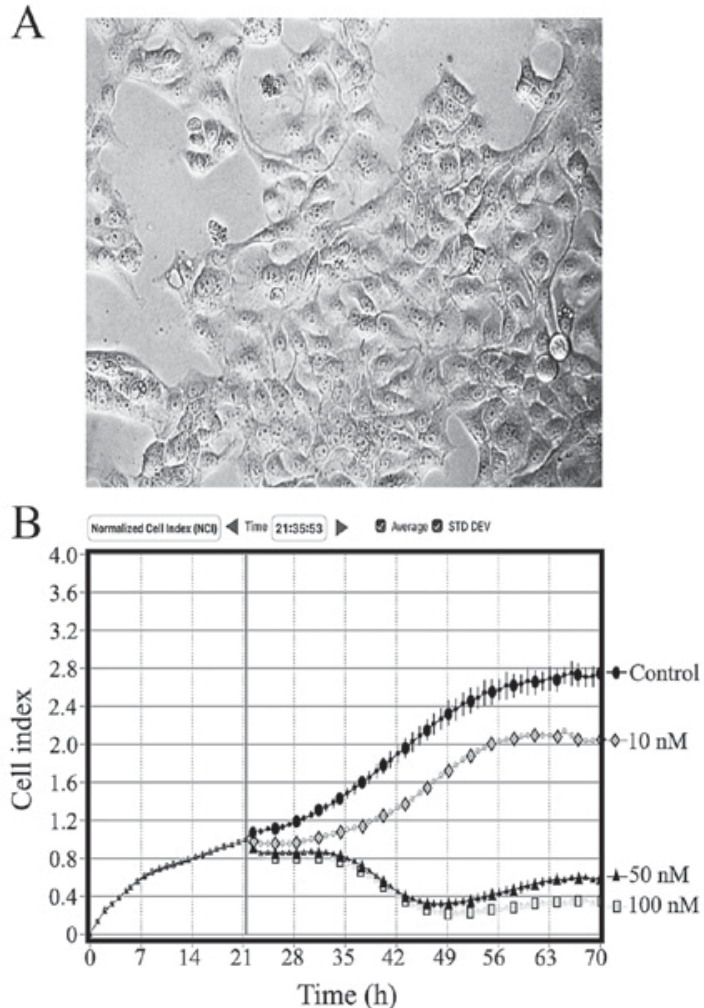
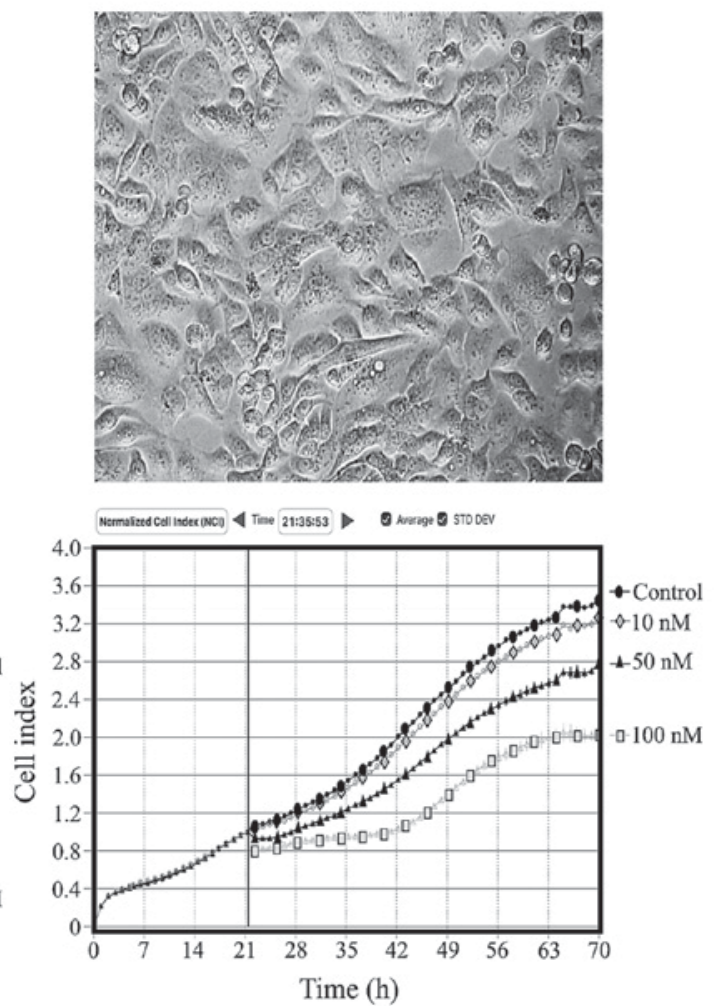

Figure 1. Differences in morphology and growth between HCC1806 and HCC1806-TxR cells. (A) The establishment of a drug-resistant phenotype in HCC1806 cells was associated with alterations to cell morphology. HCC1806-TxR cells (left) exhibited an increasingly oval shape, an enlarged size and a increased nucleus/cytoplasm ratio compared with the parental HCC1806 cells (right). (B) Growth kinetics of HCC1806 and HCC1806-TxR cells treated with a range of paclitaxel concentrations. The normal growth of the TxR subline was similar to the HCC1806 parental line; however, when treated with paclitaxel, the relative growth was greater in the TxR cells. TxR, taxol resistant.

with paclitaxel, a difference in growth kinetics between the TxR and parental HCC1806 cells was also detected (Fig. 1B), which was consistent with the MTS-based cytotoxicity data (Table II).

Paclitaxel induced cell accumulation in M-phase and apoptosis in parental, but not TxR, HCC1806 cells. As the major mechanism for the action of paclitaxel is the inhibition of tubulin depolymerization to induce apoptosis due to 'mitotic catastrophe', the ability of paclitaxel to induce the accumulation of cells in M-phase in parental vs. paclitaxel-resistant HCC1806 cells was compared. pH3 S10 staining was combined with propidium iodide DNA staining to count the number of mitotic cells by flow cytometry. An increase of the pH3 S10-positive (i.e., mitotic) HCC1806 cells was observed subsequent to 10 or
1,000 nM paclitaxel exposure (Fig. 2). In contrast, the number of mitotic paclitaxel-treated HCC1806-TxR cells was significantly less when compared with parental cells $(\mathrm{P}<0.001$ for 10 and 1,000 nM; Fig. 2).

To assess the ability of paclitaxel to induce apoptosis in parental vs. TxR HCC1806 cells, the expression of cleaved caspase-3 and PARP, specific markers for apoptosis, was observed. An increase in the cleavage of PARP and caspase-3 was detected in paclitaxel-treated HCC1806 cells, reflecting the ability of paclitaxel to induce apoptosis in HCC1806 parental cells (Fig. 3A). In contrast, relatively low cleavage of PARP and caspase-3 were observed in paclitaxel-treated HCC1806-TxR cells (Fig. 3B), thereby confirming the cytotoxicity MTS-based data by indicating the resistance of the HCC1806-TxR subline to paclitaxel. 


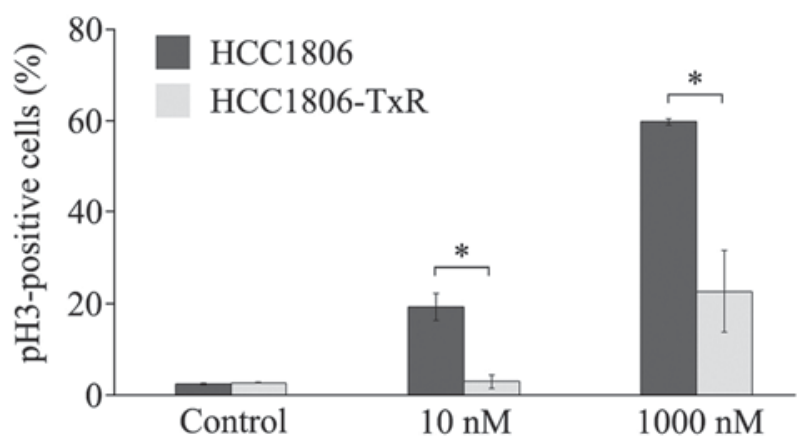

Figure 2. Relative M-phase distribution of HCC1806 and HCC1806-TxR cells following exposure to PTX. The number of mitotic cells following PTX exposure for $48 \mathrm{~h}$, as determined with $\mathrm{pH} 3$ staining in flow cytometry. Values are means \pm standard deviation $(\mathrm{n}=3)$. "P $<0.001$. TxR, taxol resistant; PTX, paclitaxel; $\mathrm{pH} 3$, phosphorylated histone subunit 3 .
A

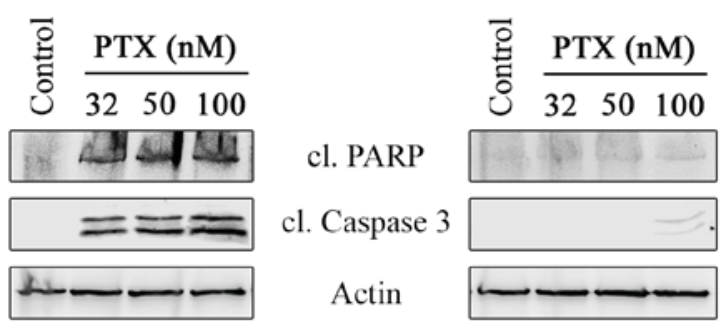

Figure 3. PTX induces the apoptosis of HCC1806 parental cells, and not HCC1806-TxR cells. Western blot analysis of (A) HCC1806 and (B) HCC1806-TxR cells for cleaved forms of PARP and caspase-3, markers of apoptotic cell death, following the treatment with dimethyl sulfoxide or PTX for $48 \mathrm{~h}$. $\beta$-actin was used as a loading control. PTX, paclitaxel; TxR, taxol resistant; PARP, poly(ADP-ribose) polymerase; cl., cleaved.

The expression of chemoresistance-associated genes is altered in HCC1806-TxR cells. As the resistance of patient tumors to chemotherapeutic agents is highly dependent on the activities of the transporters that efflux drugs from tumor cells, the expression of the MDR-1, MRP-1 and ABCG2 ABC transporter proteins in HCC1806-TxR cells was assessed. Western blot analysis revealed the overexpression of the MDR-1 and MRP-1 proteins in HCC1806-TxR cells when compared with the parental HCC1806 cells (Fig. 4). However, the expression level of another protein associated with the MDR phenotype, ABCG2, was unchanged between the parental and TxR lines.

Since a potential mechanism for MDR-1 overexpression in paclitaxel-resistant cells is the induction by Y-box-binding protein 1 (YB-1), which binds to a cis-acting element of the MDR-1 promoter to increase MDR-1 mRNA expression (11), YB-1 mRNA levels were compared between parental HCC1806 cells and the TxR subline. There was an increase (3.6-fold) of YB-1 mRNA expression in TxR-cells when compared with the parental HCC1806 cells (Table III). Similarly, a number of MRP mRNAs were observed to be overexpressed in HCC1806-TxR cells when compared with the parental HCC1806 cells (Table III). In TxR cells, the levels of MRP-1, -5, and -6 were elevated to 2.3, 15.7 and 5.7-fold, respectively. As paclitaxel-induced cell death is associated with the activation of apoptosis mechanisms, the expression of the apoptosis-related genes, Bcl-2 associated X (Bax), Bcl-2,

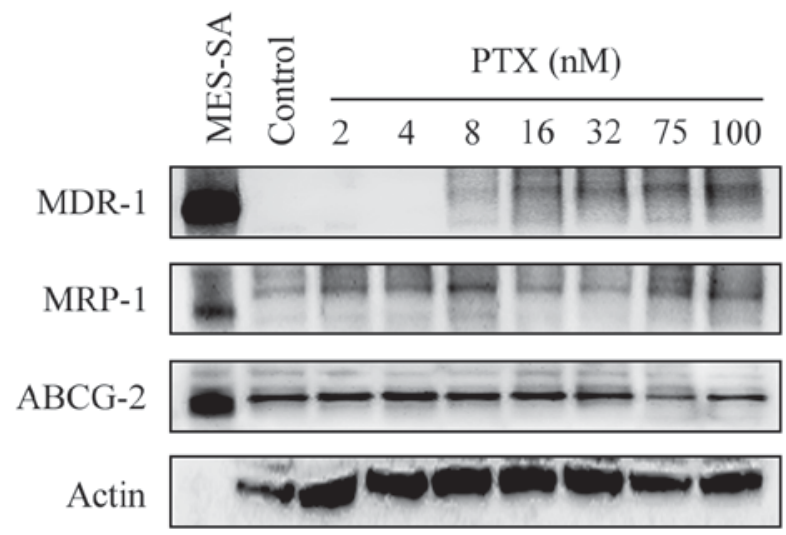

Figure 4. Expression of MDR-associated proteins in HCC1806-TxR cells. The expression of MDR-1 and MRP-1 increased in a dose-dependent manner in paclitaxel-treated HCC1806-TxR cells, whereas the expression of ABCG-2 remained unchanged. The lysate of MES-SA cells was used as a positive control for the expression of the MDR-associated proteins; $\beta$-actin was used as a loading control. MDR, multidrug resistance; TxR, taxol resistant; MDR-1, P-glycoprotein; MRP-1, multidrug resistance-associated protein-1; ABCG-2, ABC subfamily G member 2.

caspase- 8 and Fas, were compared in parental vs. TxR cells. The expression of Bax and caspase- 8 mRNA were unchanged in resistant cells, but a trend towards the downregulation of Fas was observed when compared with parental cells. In contrast, Bcl-2 expression was upregulated in the TxR subline (Table III).

Intracellular drug concentration. As cellular mechanisms for drug resistance include a decline of intracellular drug concentrations as a result of increased efflux by overexpressed $A B C$ proteins, and considering the overexpression of MDR-1 and MRP-related genes in the TxR cells, the intracellular paclitaxel concentrations in HCC1806 cells were compared with HCC1806-TxR cells. As presented in Fig. 5, at $2 \mathrm{~h}$ of paclitaxel exposure, HCC1806-TxR-cells contained $\sim 540 \mathrm{ng}$ paclitaxel, which was much lower than in the parental HCC1806 cells $(2,930$ ng; $\mathrm{P}<0.05)$.

\section{Discussion}

In the present study, a paclitaxel-resistant basal-like TNBC cell line was established from the parental HCC1806 cell line. The paclitaxel $\mathrm{IC}_{50}$ value for HCC1806-TxR cells was $\sim 17$-fold higher when compared with parental HCC1806 cells. Of note, the paclitaxel resistance remained stable after 1 month of culturing without paclitaxel and following storage at $-80^{\circ} \mathrm{C}$ for 6 months. HCC1806-TxR cells exhibited alterations to cellular morphology (for example enlarged, oval-shaped) when compared with parental cells. Additionally, increased growth was observed in HCC1806-TxR cells exposed to paclitaxel compared with the parental HCC1806 cells.

Paclitaxel is a commonly used chemotherapeutic drug for the treatment of patients with a range of types of cancer, including breast, ovarian and lung cancer (12-14). The molecular mechanism for the action of paclitaxel is its ability to bind microtubules and induce their stabilization, thus preventing their disassembly during mitosis $(3,5)$. Therefore, in paclitaxel-treated cells, microtubules become locked in a 
Table III. Alterations in the expression level of chemoresistance and apoptosis associated genes in HCC1806-TxR cells relative to HCC1806 cells, as determined by reverse transcriptionquantitative polymerase chain reaction.

\begin{tabular}{lc}
\hline Gene & Fold change \\
\hline P-glycoprotein & 1.73 \\
MRP-1 & 2.3 \\
MRP-2 & 1.33 \\
MRP-3 & 0.19 \\
MRP-4 & 1.28 \\
MRP-5 & 15.74 \\
MRP-6 & 5.76 \\
MRP-7 & 1.51 \\
Bcl-2 & 1.65 \\
Bcl-2 associated X & 1.12 \\
Fas & 0.63 \\
Caspase-8 & 0.98 \\
Y-box binding protein 1 & 3.59 \\
\hline
\end{tabular}

TxR, taxol resistant; MRP, multidrug resistance-associated protein.

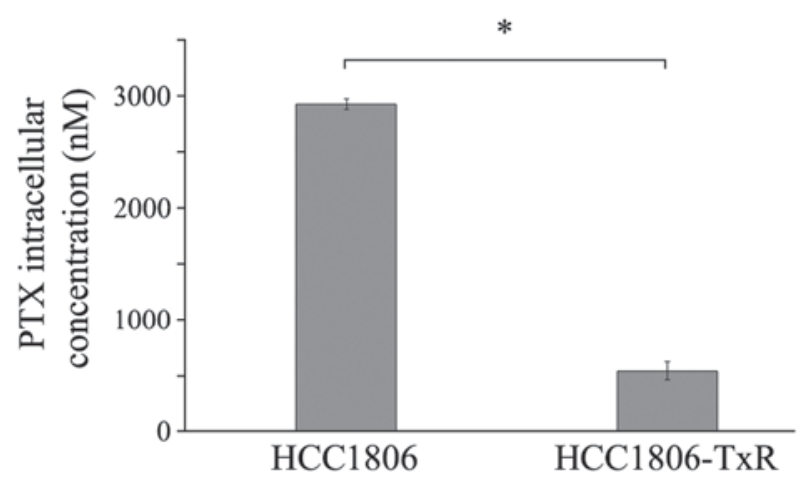

Figure 5. The intracellular PTX concentration following a $2 \mathrm{~h}$ exposure to 100 nM PTX. The concentration of PTX was measured by solid-phase extraction high performance liquid chromatography. PTX, paclitaxel. ${ }^{*} \mathrm{P}<0.001$.

polymerized state, which leads to $\mathrm{G} 2 / \mathrm{M}$ arrest, induces the accumulation of cells in M-phase and leads to cell death via apoptosis (15-18). Thus, a substantial decrease of mitotic and apoptotic cell amount in TxR-subline after paclitaxel exposure was expected. Indeed, a substantial decrease of pH3 S10-positive (i.e., mitotic) cells (Fig. 2) and a low level of PARP and caspase-3 cleavage of in paclitaxel-treated HCC1806-TxR cells was observed when compared with parental HCC1806 cells (Fig. 3B). This data was consistent with the cytotoxicity MTS-based data, indicating the resistance of the HCC1806-TxR subline to paclitaxel.

Additionally, HCC1806-TxR exhibited a cross-resistance to other types of chemotherapeutic agents, including vinblastine, and etoposide and doxorubicin topoisomerase type II inhibitors. The resistance indexes for the drugs indicated above were $14.65,4.36$ and 3.18 , respectively. This data is consistent with previous study, indicating that cancer cells in culture becoming resistant to a single drug may become resistant to a class of drugs with a similar mechanism of action as well (19). In addition, cancer cells may acquire a cross-resistance to structurally and mechanistically unrelated drugs; this phenomenon is known as MDR. For example, McDonald et al previously demonstrated that docetaxel-resistant MDA-MB and MCF-7 breast cancer cells developed a cross-resistance to paclitaxel and vincristine (20), concordant to the findings of the present study. Multiple reports have indicated that resistant sublines commonly express MDR-1 and MRP proteins $(9,21,22)$. Clinical studies also report the development of cross-resistance to multiple anticancer agents following the initial success of chemotherapy $(23,24)$, which may also be due to the overexpression of MDR-1 and MRPs.

Thus, the molecular mechanism of cross-resistance of HCC1806-TxR to vinblastine and topoisomerase type II inhibitors may be due to the increased expression of $\mathrm{ABC}$ transporters, important mediators of drug efflux. An increased expression of MDR-1 and MRP-1 proteins in HCC1806-TxR cells was observed (Fig. 4), which may lead to the increased efflux of paclitaxel and other types of chemotherapeutic drugs (for example alkylating agents, topoisomerase type II inhibitors), resulting in MDR (Fig. 5).

In order to investigate the genes involved in paclitaxel resistance, the gene expression profile between HCC1806 and HCC1806-TxR cells was compared. MDR-1, MRP-1, -5 and -6 were upregulated in the HCC1806-TxR subline, suggesting that these factors served a function in the observed MDR phenotype. The increased activity of ABC transporters in the HCC1806-TxR subline was additionally confirmed by a marked (5.4-fold) decrease in the intracellular paclitaxel content in TxR-cells at $2 \mathrm{~h}$ of paclitaxel exposure when compared with parental HCC1806 cells (Fig. 5), thus indicating an increased efflux of chemotherapeutic drugs in the HCC1806-TxR subline. Furthermore, differences in expression of genes associated with apoptosis between the parental and TxR-cells, including Bcl-2 and Fas, were also detected. This data may also explain the low expression of apoptotic markers (cleaved PARP and caspase-3) in TxR cells subsequent to paclitaxel exposure when compared with parental HCC1806 cells (Fig. 3).

In conclusion, a HCC1806 subline was established with high resistance to paclitaxel, which also harbored a cross-resistance to diverse types of chemotherapeutic agents, including those with similar and different modes of action to paclitaxel. The MDR phenotype was associated with MDR-1, MRP-1, -5 and -6 overexpression, thus providing an effective efflux of anticancer drugs from HCC1806-TxR cancer cells. In addition, the TxR breast cancer subline also resisted apoptosis subsequent to the exposure to paclitaxel. This may be due to the downregulation of pro-apoptotic proteins (Fas) and the upregulation of anti-apoptotic proteins (Bcl-2). Paclitaxel resistance remained stable subsequent to 1 month of culturing without paclitaxel and following prolonged storage at $-80^{\circ} \mathrm{C}$. Taken together, the established MDR in a HCC1806-derived breast cancer subline may be appropriate for in vitro screenings of novel anticancer agents for overcoming MDR-mediated mechanisms in TNBC.

\section{Acknowledgements}

The present study was supported by a grant from the Russian Science Foundation (grant no. 14-15-00342). 


\section{References}

1. Dent R, Trudeau M, Pritchard KI, Hanna WM, Kahn HK, Sawka CA, Lickley LA, Rawlinson E, Sun P and Narod SA: Triple-negative breast cancer: Clinical features and patterns of recurrence. Clin Cancer Res 13: 4429-4434, 2007.

2. Kassam F, Enright K, Dent R, Dranitsaris G, Myers J, Flynn C, Fralick M, Kumar R and Clemons M: Survival outcomes for patients with metastatic triple-negative breast cancer: Implications for clinical practice and trial design. Clin Breast Cancer 9: 29-33, 2009.

3. Jordan MA and Wilson L: Microtubules as a target for anticancer drugs. Nat Rev Cancer 4: 253-265, 2004.

4. Dumontet $\mathrm{C}$ and Jordan MA: Microtubule-binding agents: A dynamic field of cancer therapeutics. Nat Rev Drug Discov 9: 790-803, 2010

5. Parker A, Kavallaris M and McCarroll JA: Microtubules and their role in cellular stress in cancer. Front Oncol 4: 153, 2014.

6. Bosch A, Eroles P, Zaragoza R, Viña JR and Lluch A Triple-negative breast cancer: Molecular features, pathogenesis, treatment and current lines of research. Cancer Treat Rev 36: 206-215, 2010.

7. Yu KD, Zhu R, Zhan M, Rodriguez AA, Yang W, Wong S, Makris A, Lehmann BD, Chen X, Mayer I, et al: Identification of prognosis-relevant subgroups in patients with chemoresistant triple-negative breast cancer. Clin Cancer Res 19: 2723-2733, 2013.

8. Ullah MF: Cancer multidrug resistance (MDR): A major impediment to effective chemotherapy. Asian Pac J Cancer Prev 9: 1-6, 2008.

9. Hasanabady $\mathrm{MH}$ and Kalalinia F: ABCG2 inhibition as a therapeutic approach for overcoming multidrug resistance in cancer. J Biosci 41: 313-324, 2016.

10. Livak KJ and Schmittgen TD: Analysis of relative gene expression data using real-time quantitative PCR and the 2(-Delta Delta C(T)) Method. Methods 25: 402-428, 2001.

11. Ohga T, Uchiumi T, Makino Y, Koike K, Wada M, Kuwano M and Kohno K: Direct involvement of the Y-box binding protein YB-1 in genotoxic stress-induced activation of the human multidrug resistance 1 gene. J Biol Chem 273: 5997-6000, 1998.

12. Holmes FA, Walters RS, Theriault RL, Forman AD, Newton LK, Raber MN, Buzdar AU, Frye DK and Hortobagyi GN: Phase II trial of taxol, an active drug in the treatment of metastatic breast cancer. J Natl Cancer Inst 83: 1797-1805, 1991.
13. Brown T, Havlin K, Weiss G, Cagnola J, Koeller J, Kuhn J, Rizzo J, Craig J, Phillips J and Von Hoff D: A phase I trial of taxol given by a 6-hour intravenous infusion. J Clin Oncol 9: 1261-1267, 1991.

14. McGuire WP, Rowinsky EK, Rosenshein NB, Grumbine FC, Ettinger DS, Armstrong DK and Donehower RC: Taxol: A unique antineoplastic agent with significant activity in advanced ovarian epithelial neoplasms. Ann Intern Med 111: 273-279, 1989.

15. Fuchs DA and Johnson RK: Cytologic evidence that taxol, an antineoplastic agent from Taxus brevifolia, acts as a mitotic spindle poison. Cancer Treat Rep 62: 1219-1222, 1978.

16. Schiff PB, Fant J and Horwitz SB: Promotion of microtubule assembly in vitro by taxol. Nature 277: 665-667, 1979.

17. Haldar S, Jena $\mathrm{N}$ and Croce $\mathrm{CM}$ : Inactivation of Bcl-2 by phosphorylation. Proc Natl Acad Sci USA 92: 4507-4511, 1995.

18. Weaver BA: How Taxol/paclitaxel kills cancer cells. Mol Biol Cell 25: 2677-2681, 2014.

19. Guo B, Villeneuve DJ, Hembruff SL, Kirwan AF, Blais DE, Bonin M and Parissenti AM: Cross-resistance studies of isogenic drug-resistant breast tumor cell lines support recent clinical evidence suggesting that sensitivity to paclitaxel may be strongly compromised by prior doxorubicin exposure. Breast Cancer Res Treat 85: 31-51, 2004

20. McDonald SL, Stevenson DA, Moir SE, Hutcheon AW, Haites NE, Heys SD and Schofield AC: Genomic changes identified by comparative genomic hybridization in docetaxel-resistant breast cancer cell lines. Eur J Cancer 41: 1086-1094, 2005.

21. Sharom FJ: ABC multidrug transporters: Structure, function and role in chemoresistance. Pharmacogenomics 9: 105-127, 2008.

22. Kim KY, Kim SH, Yu SN, Park SK, Choi HD, Yu HS, Ji JH, Seo YK and Ahn SC: Salinomycin enhances doxorubicin-induced cytotoxicity in multidrug resistant MCF-7/MDR human breast cancer cells via decreased efflux of doxorubicin. Mol Med Rep 12: 1898-1904, 2015.

23. Kröger N, Achterrath W, Hegewisch-Becker S, Mross K and Zander AR: Current options in treatment of anthracycline-resistant breast cancer. Cancer Treat Rev 25: 279-291, 1999.

24. Yonemori K, Katsumata N, Uno H, Matsumoto K, Kouno T, Tokunaga S, Yamanaka Y, Shimizu C, Ando M, Takeuchi M and Fujiwara Y: Efficacy of weekly paclitaxel in patients with docetaxel-resistant metastatic breast cancer. Breast Cancer Res Treat 89: 237-241, 2005. 